\title{
Sphaeroceridae (Diptera) in burrows of rabbit and fox in central Bohemia (Czech Republic), with description of a new species of Minilimosina Roháček
}

\author{
Jindřich Roháček
}

Roháček, J. 2019: Sphaeroceridae (Diptera) in burrows of rabbit and fox in central Bohemia (Czech Republic), with description of a new species of Minilimosina Roháček. — Entomol. Fennica 30: 97-113. https://doi.org/10.33338/ ef.84085

\begin{abstract}
The communities of Sphaeroceridae in burrows of European Rabbit Oryctolagus cuniculus and Red Fox Vulpes vulpes in central Bohemia (the Czech Republic) are described including number, dominance and constancy of species and compared by means of a similarity index. A total of 17 species were recorded from burrows of rabbit and 9 from those of fox. Spelobia talparum (Richards, 1927) and S. pseudonivalis (Dahl, 1909) are considered pholeobiont (= eucoenic) and Spelobia czizeki (Duda, 1918) pholeophilous to pholeobiont species in this habitat. Comparison of these two communities with those recorded from other mammal subterraneous habitats in Europe revealed that most similar are those from the same locality irrespective of the host mammal species or the size of the burrow. The species spectrum of European Sphaeroceridae recorded from mammal burrows is reviewed and discussed. Minilimosina (Minilimosina) speluncana $\mathbf{s p .}$ n. is described on males found in rabbit burrow and its relationship and habitat association are discussed.
\end{abstract}

J. Roháček, Silesian Museum, Nádražní okruh 31, CZ-746 01 Opava, Czech Republic.E-mail: rohacek@szm.cz

Received 3 April 2018, accepted 28 June 2018

\section{Introduction}

While the communities of flies (Diptera), including regularly representatives of the family Sphaeroceridae, have previously been rather often studied in nests and runs of small mammals in Europe (Falcoz 1915, 1921, Richards 1930, Davis 1934, Hackman 1963a, b, 1965, 1967, Baumann 1977, Vysotskaya 1978, 1981, Roháček 1984, Krivokhatsky 1989, Krivokhatsky \& Nartshuk 2007, Hutson 2010) those living in burrows and tunnels of larger mammals, such as rabbit, fox and badger, have hitherto received little attention. Although also these large burrows are undoubtedly inhabited by a rich dipterous community, there are very few reliable data because most, particularly older, studies were mainly devoted to beetles (Coleoptera) and the dipterous component was partly or wholly neglected. For example, Falcoz (1915) recorded only a few flies from rabbit and badger burrows but no Acalyptrate Diptera (including Sphaeroceridae). More detailed information on Diptera in this habitat was provided by British authors, particularly on flies in rabbit and badger burrows while data from burrows of fox remain extremely scarce. Richards (1930) processed material of Sphaeroceridae collected by him in rabbit burrows in 


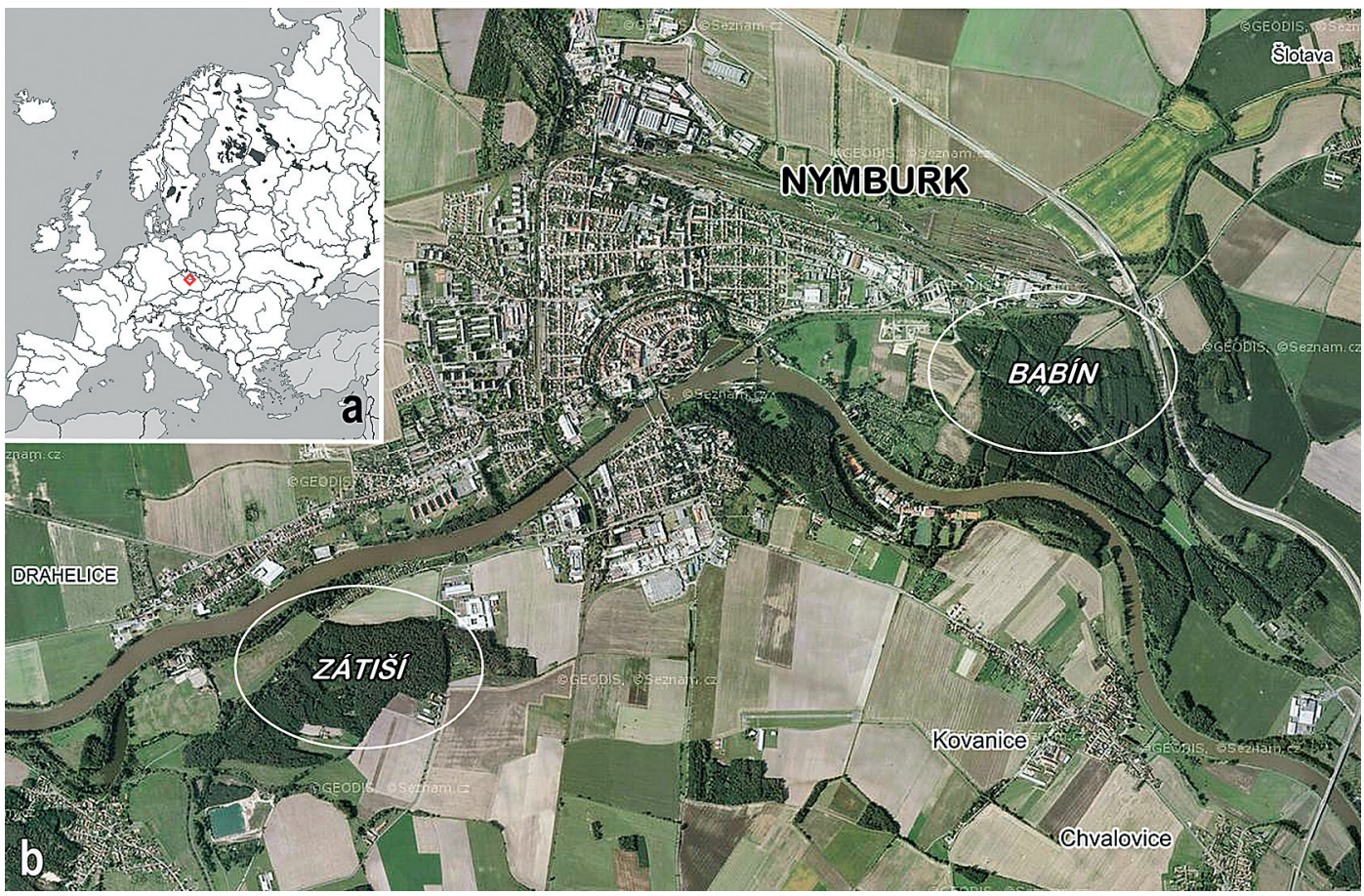

Fig. 1. - a. Position of the Nymburk town in Europe. - b. Aerial view of the Nymburk vicinity with localities of this study. Sources: Fauna Europaea (a) and https://mapy.cz (b).

England and presented his results including classification of association of recorded species with this subterraneous habitat.

However, by far the largest amount of data on flies (including numerous Sphaeroceridae) in nests and burrows (including those of rabbit and fox) was obtained by E. B. Basden in the years 1931-1935 (see Rotheray 1989), but a great deal of them remained unpublished until Rotheray (1991) summarized his results. The latter study is the most detailed source of knowledge of Sphaeroceridae (and other Diptera) occurring in rabbit burrows while it contains only a single record from fox burrows. Okely (1974) obtained puparia of Sphaeroceridae by placing a breeding substrate (boiled grass cuttings) in open plastic containers in the burrow tunnels of rabbits.

However, it is not clear from her paper on (only) previously undescribed puparia which other species she also reared from this habitat. Nevertheless, it is probable that except for Spelobia parapusio (Dahl, 1909) (which she reared from decayed fungi) all other listed species originated from rabbit burrows. The dipterous fauna in burrows of European Badger (Meles meles (Linnaeus, 1758)) has been studied more recently in Britain (Payne 1979, 1982, Hancox 1988) and Ireland (Sleeman \& Bond 2003) but also these studies recorded only a few species of Sphaeroceridae.

This paper is devoted to results of analysis of a relatively small but interesting material of Sphaeroceridae collected by the $\mathrm{Czech}$ coleopterist $\mathrm{L}$. Daněk in burrows of European Rabbit (Oryctolagus cuniculus (Linnaeus, 1758)) and Red Fox (Vulpes vulpes (Linnaeus, 1758)) in the vicinity of Nymburk in Central Bohemia (the Czech Republic) in the 1990's. The communities of Sphaeroceridae found in these subterranean habitats in this locality are described and compared mutually and with those known from rabbit burrows from Great Britain (Richards 1930, Okely 1974, Rotheray 1991) but also with those recorded from runs and nests of other small mammals throughout Europe. Because, surprisingly, a new species of the subgenus Minilimosina (Minilimosina) Roháček, 1983 was found among specimens from rabbit burrows, it is described in 
full here to make its name available as an additional member of the assemblage of microcavernicolous Sphaeroceridae.

\section{Materials and methods}

\subsection{Material}

The Sphaeroceridae examined comprise 18 samples (229 specimens) from burrows of European Rabbit (Oryctolagus cuniculus) and 13 samples (212 specimens) from burrows of Red Fox (Vulpes vulpes). All specimens were originally preserved in $80 \%$ ethanol but a few specimens were dried and mounted on pinned triangular cards or transferred to glycerine in the course of this study. The material, including type specimens of the new species, is deposited in the Silesian Museum, Opava, Czech Republic (SMOC).

\subsection{Localities}

All specimens were collected by the Czech amateur coleopterist L. Daněk in the environment of the town Nymburk in Central Bohemia, the Czech Republic (Fig. 1a) in 1995-1999. The majority of them (possibly all, but in a number of samples the precise site is not specified) originate from two forested areas in the close vicinity of Nymburk called "Zátišsi'” (about $2.5 \mathrm{~km}$ SW from Nymburk town centre, $50^{\circ} 10^{\prime} 13^{\prime}$ 'N, $15^{\circ} 01^{\prime}$ 07”E, ca 195 ma. s. 1.) and "Babín" (about $2 \mathrm{~km} \mathrm{E}$ from Nymburk town centre, $50^{\circ} 11^{\prime} 06^{\prime \prime} \mathrm{N}$, $15^{\circ} 04^{\prime} 17^{\prime}$ 'E, ca $190 \mathrm{~m}$ a. s. 1.), see Fig. 1b. Only one specimen was collected in (a fox burrow) the locality Nymburk-Dvory (about $4.5 \mathrm{~km}$ NW from Nymburk town centre, $50^{\circ} 12^{\prime} 43^{\prime \prime} \mathrm{N}$, $14^{\circ} 59^{\prime} 35^{\prime \prime} \mathrm{E}$, ca $190 \mathrm{~m}$ a. s. 1 ., not in the map in Fig. 1b).

\subsection{Collecting methods}

The majority of specimens was captured by means of unbaited pitfall traps (small jars with ethylene glycol or glycerine) installed in the entrance part of burrows, originally aimed to cap- ture beetles. The traps were exposed for a week or less. The dates on labels are those when traps were emptied. Only a few specimens were handcollected in burrows by means of a pooter (aspirator) (information obtained from the collector).

\subsection{Methods of species community analyses}

The structure and comparison of communities in both types of burrows (i.e. those of fox and rabbit) were expressed by means of the simple quantitative characters: 1) the number of species, 2) the species abundance (n), dominance (D) and constancy $(\mathrm{C})$ and 3 ) index of similarity (S). Detailed methods and formulae have been given by Spelleberg (1991) and Begon et al. (1996).

The dominance of individual species is expressed as: $\mathrm{D}_{\mathrm{i}}=\mathrm{N}_{\mathrm{i}} / \mathrm{N} .100(\%)$, where $\mathrm{N}=$ the total number of specimens, $\mathrm{N}_{\mathrm{i}}=$ number of specimens of $1^{\text {th }}$ species. In line with Spelleberg (1991) and Begon et al. (1996), the species with $\mathrm{D} \geq 10 \%$ have been considered eudominant, those with $\mathrm{D}=$ $5-10 \%$ dominant, those with $\mathrm{D}=2-5 \%$ subdominant, those with $\mathrm{D}=1-2 \%$ recedent and those with $\mathrm{D} \leq 1 \%$ subrecedent.

The constancy is the percentage of samples in which the species occurred, out of the total number of studied samples: $\mathrm{C}=\mathrm{S}_{\mathrm{s}} / \mathrm{S} \times 100(\%)$, where $\mathrm{S}=$ the total number of samples from burrows, $\mathrm{S}_{\mathrm{s}}=$ the number of samples in which the species was found. Species with $50 \leq \mathrm{C}<75$ have been considered as constant, those with $\mathrm{C} \geq 75$ as euconstant.

Index of similarity: $\mathrm{S}=2 \mathrm{C} / \mathrm{A}+\mathrm{B} .100(\%)$, where $\mathrm{A}=$ number of species found in burrows of first host species, $\mathrm{B}=$ number of species found in burrows of second host species and $\mathrm{C}=$ number of species occurring simultaneously in both types of burrow (A and B).

\subsection{The assessment of the affinity of species to mammal burrows}

The affinity of individual species to mammal burrows has been judged according to the knowledge of their biology, autecology and distribution. The classification system proposed long ago by Fal$\operatorname{coz}(1915: 70)$ is followed but it is expanded by 


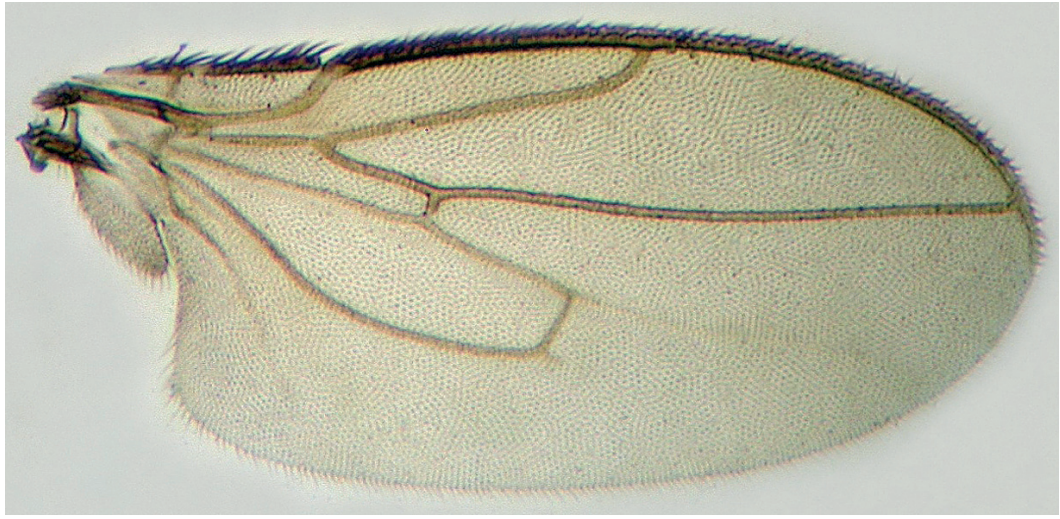

Fig. 2. Minilimosina (M.) speluncana sp. $\mathbf{n}$., male paratype, wing (length ca $1.4 \mathrm{~mm}$ ). an additional category (coeno-neutral, thus similarly as originally proposed by Roháček \& Máca (1982) for species living in peat-bogs). Therefore, four categories are differentiated according to the degree of species association with microcavernicolous habitats:

- Pholeobiont (species preferably to exclusively associated with burrows)

- Pholeophilous (associated with burrows but also with related subterraneous and terricolous habitats like caves and various crevices including those under layers of rotten vegetation)

- Pholeoneutral (species with wide habitat tolerance utilizing various habitats and successfully living also in burrows)

- Pholeoxenous (species occurring in burrows only by chance, not developing there)

These categories can be compared with those generally used in North Europe (e.g. Krogerus 1960) and adopted also by Hackman (1963b, without using the term acoenic) as follows: pholeobiont $=$ eucoenic (euzön), pholeophilous = tychocoenic (tychozön), pholeoneutral $=$ acoenic (azön), pholeoxenous $=$ xenocoenic $($ xenozön $)$.

\subsection{Taxonomic methods}

Methods used to examine and describe the new species are the same as in Roháček (2016). Morphological terminology, including abbreviations, are also those used and explained in the latter paper and/or in the chapter Sphaeroceridae in Man- ual of Palaearctic Diptera (Roháček 1998). Nomenclature follows that used in Roháček et al. (2001) and Marshall et al. (2011).

\subsection{Presentation of material data}

For each species specimens from rabbit and fox burrows are listed separately, with abbreviated names of localities (B - "Babín" forest, $\mathrm{N}=$ Nymburk, ND = Nymburk-Dvory, Z = "Zátiší1" forest), full collecting dates and numbers of specimens (males and females).

\section{Results}

\subsection{Description of Minilimosina (Minilimosina) speluncana sp. $\mathrm{n}$. (Figs 2, 3a-f, 4a-c)}

Type material. Holotype $\widehat{\nearrow}$ : Labelled "Bohemia: Nymburk, 5.11.1996, Babín, JUDr. L. Daněk lgt.", "opuštěné nory divok. králíků" and "HOLOTYPUS $\widehat{\jmath}$, Minilimosina (M.) speluncana sp. n., J. Roháček det. 2018” (red label). The holotype specimen is intact, preserved in pinned microvial in glycerine (SMOC). Paratype $\sigma^{\lambda}$ : Same label data as for holotype but with yellow PARATYPUS label, dissected, with all parts of body preserved in pinned microvial in glycerine except for abdomen (dissected for genitalic study) being in glycerine in a plastic coalesced tube pinned below the microvial) (SMOC).

The precise type locality is as follows: Czech Republic: C. Bohemia: Nymburk, Babín (= a fo- 
rest ca $2 \mathrm{~km}$ E from Nymburk town centre), $50^{\circ} 11^{\prime} 06^{\prime \prime} \mathrm{N}, 15^{\circ} 04^{\prime} 17^{\prime \prime} \mathrm{E}$, ca $190 \mathrm{~m}$ a. s. 1.

Diagnosis. The new species is similar to Minilimosina baculum Marshall, 1985 and $M$. caelator Roháček, 1988 but differs from the former (M. baculum) in having only 3 small ifr, male mid femur with only 3 strong curved ventral setae in proximal half (Fig. 4a), male S5 with multiple comb of spines on (longer) posteromedial lappet lacking medial robust spine (Fig. 3f), gonostylus with more rounded anterior clubbed lobe and with external ventral spinose projection and 1 long posterior seta on posterior lobe (Fig. 3d), postgonite more slender and with plain (not serrate) apex (Fig. 3c). From M. caelator it differs by longer setae on mid tibia (particularly posterodorsal proximal seta markedly longer, see Fig. $4 \mathrm{~b}$ ), only 6 rows of ac microsetae, male S5 armature (as above), male S6 unmodified (without posteromedial chisel-like process), anterior lobe of gonostylus (as above), posterior lobe of gonostylus with some micropubescence and as above, postgonite apically simple (not tuberculate).

Description. Male. Total body length 1.45$1.66 \mathrm{~mm}$ (larger one of the holotype); general colour brown to dark brown, subshining to dull, with dark brownish grey microtomentum. Head dark brown and largely dull, only occiput more shining. Frons microtomentose and dull; orbits relatively broad; interfrontalia and frontal triangle indistinctly delimited; interfrontalia surrounded by dark brown band (as wide as orbit) contrasting with paler orbits and medial area between dark interfrontal bands; frontal lunule distinctly lighter (ochreous brown) than adjacent frons and dull; ocellar triangle small, not darker than frontal triangle. Cephalic chaetotaxy: all setae short; pvt present but reduced to small slightly convergent setulae; occe and occi also small, subequal, about twice longer than pvt; vte and vti relatively strong (the latter longest of cephalic setae); 2 strongly exclinate ors (posterior slightly longer), both ors and also oc somewhat shorter than vte; $1-2$ very minute ads on orbit in front of anterior ors; 3 small subequal ifr; g small but longer than peristomal setulae; vi strong, almost as long as vti. Face and gena brown; face with subshining concavities below antennae and distinct (more microtomentose) medial carina being most prominent dorsally between antennae; gena uniformly brown, but postgena with posterior perpendicular blackish brown stripe prolonged also on occiput at posterior margin of eye; vibrissal angle slightly paler than rest of gena. Eye subcircular $(21: 18)$ and slightly convex; its longest diameter about 2.3 times as long as smallest genal height, i.e. gena relatively high. Mouthparts brown including palpus, only clypeus dark brown. Antenna dark brown; $1^{\text {st }}$ flagellomere hardly paler than pedicel, finely pubescent. Arista about 2.8 times as long as antenna, with pale, medium long ciliation.

Thorax dark brown, notopleural area and sutures between pleural sclerites paler brown. Mesonotum brown microtomentose and subshining; pleural part of thorax largely dull due to denser microtomentum, only small spot on anterodorsal corner of sternopleuron (Fig. 4c) shining. Scutellum rounded triangular, shorter than long, rather flat on disc. Thoracic chaetotaxy: all macrosetae on scutum short; only $1 \mathrm{dc}$ in prescutellar position (much shorter than scutellum); ac microsetae in 6 rows behind suture (in 4 rows between dc); $2 \mathrm{sc}$, both relatively long, basal as long as scutellum, apical (longest thoracic seta) about 1.7-1.8 times as long as scutellum; $2 \mathrm{stpl}$ (Fig. 4c) but anterior weak, less than half length of posterior stpl.

Legs brown, only trochanters and tarsi slightly paler. Pedal chaetotaxy: fore and hind leg without peculiarities, uniformly setulose. Mid femur ventrally with only 3 curved setae in proximal two-fifths and anteriorly with 1 distinct preapical seta; in paratype with 1 enlarged anterior seta also in proximal two-fifths in addition (cf. Fig. 4a); mid tibia dorsally (Fig. 4b) with 1 short proximal anterodorsal, 1 small distal anterodorsal, 1 long (yet more) distal dorsal seta and 1 long (but shorter than adjacent dorsal seta) distal posterodorsal seta; ventral side of mid tibia (Fig. $4 a$ ) with a row of (rather weak) spinulae in distal half and 1 relatively long ventroapical seta. Ratio $\mathrm{t}_{2}: \mathrm{mt}_{2}=1.47$ (holotype) -1.54 .

Wing relatively short and broad (Fig. 2), with distinctly brownish membrane (darker than in most relatives) and veins, only $\mathrm{C}$ darker brown (darkest on $\mathrm{Cs}_{1}$ and $\mathrm{Cs}_{2}$ ). $\mathrm{C}$ far extended beyond apex of $\mathrm{R}_{4+5} ; \mathrm{R}_{2+3}$ short, basally straight but apically distinctly upcurved to $\mathrm{C}$ (more than in both closest relatives; $\mathrm{R}_{4+5}$ slightly but distinctly sinuate, with apical portion straightened. Discal (dm) cell relatively long, tapered somewhat dis- 


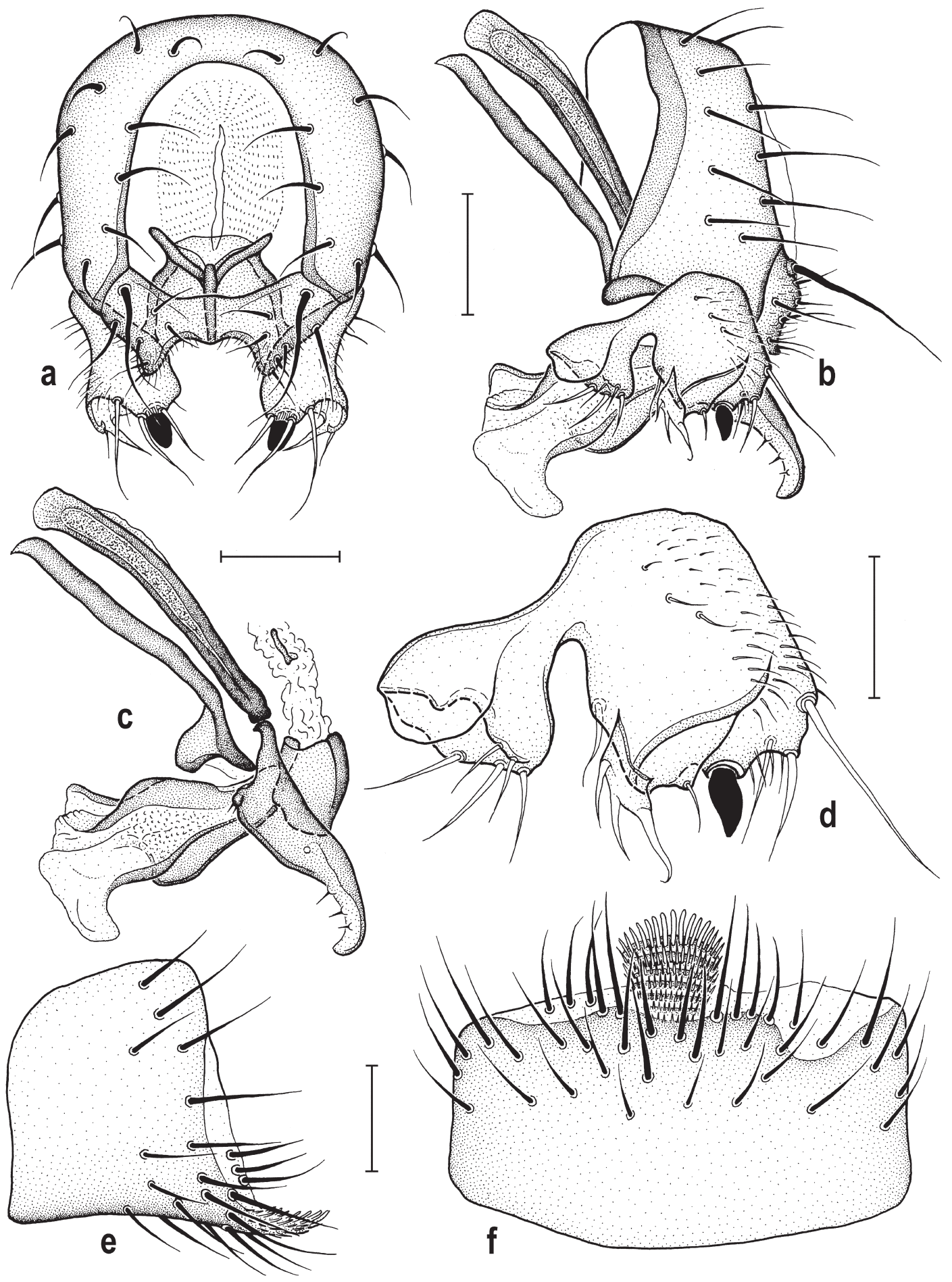

Fig. 3. Minilimosina (M.) speluncana sp. n., male paratype. - a. External genitalia, caudally. - b. Genitalia, laterally. - c. Aedeagal complex and hypandrium, laterally. - d. Gonostylus, laterally. - e. S5, laterally. - f. S5, ventrally. Scales: $0.03 \mathrm{~mm}$ (d), $0.05 \mathrm{~mm}$ (others). 
tally, with both venal processes of $\mathrm{M}$ and $\mathrm{CuA}_{1}$ beyond dm-cu short but distinct. $\mathrm{A}_{1}$ rather long, sinuate, disappearing distally; alula relatively narrow though not very small, tapered but not acute on apex. Wing measurements (measured in glycerine; higher values are of the holotype): length $1.39-1.58 \mathrm{~mm}$, width $0.50-0.69 \mathrm{~mm}, \mathrm{C}$ index $\left(\mathrm{Cs}_{2}: \mathrm{Cs}_{3}\right)=0.79-0.83$, rm $\backslash \mathrm{dm}-\mathrm{cu}: \mathrm{dm}-\mathrm{cu}$ $=2.55-2.59$. Haltere with blackish brown knob and pale brown stem.

Abdomen with all sclerites brown to dark brown. Preabdominal terga sparsely microtomentose, subshining, with rather sparse and short setae. T1+2 largest (T1 pale and partly separate from T2) preabdominal sclerite; T3-T5 distinctly shorter and more transverse than $\mathrm{T} 2$ and becoming also narrower posteriorly (T5 smallest). Preabdominal sterna S2-S4 markedly narrower and more densely setose than associated terga, becoming somewhat darker and larger posteriorly (S4 widest) but subequal in length. Pregenital sternum (S5) as large as S4 but darker, with characteristic posteromedial armature (Figs $3 \mathrm{e}, \mathrm{f}$ ) consisting of flat but relatively long lappet (somewhat widened posteriorly) covered by up to 7 combs of spinulae to spines, those in posterior comb longest and blunt but lacking the medial robust spine of $M$. baculum; setae covering posterior half of S5 distinctly longer and denser than those of closest relatives (M. baculum and $M$. caelator). Postabdominal sterna S6-S8 more or less coalesced together forming asymmetrical dark brown systernite, with S6 lying ventrolaterally, S7 laterally (both strongly asymmetrical) and S8 (more symmetrical) dorsally. S6 without ventromedial projection (hence resembling more that of $M$. baculum) and S7 with its ventral corner bent inside of postabdomen.

Genitalia. Epandrium (Fig. 3a, b) moderately long and about as high as broad, with relatively long (longer than in $M$. baculum and $M$. caelator), subequal and rather sparse setae. Cerci (Fig. 3a, b) well developed, fused medially and with epandrium but the latter fusion line distinctly delimited; each cercus somewhat projecting ventrally and with 1 very long sinuate dorsolateral seta, several short setae and some microtomentum (longest ventrally). Medandrium (= intraepandrial sclerite) medium-sized, with distinctly projecting dorsolateral corners. Hypan- drium broadly Y-shaped; its lateral sclerites externally not large and medial rod-like apodeme relatively long (Fig. 3b, c), as long as phallapodeme. Gonostylus pale-pigmented (Fig. 3a, b, d) and generally resembling that of both above relatives in having anterior clubbed lobe connected with larger posterior part (this armed with robust ventral spine) by narrow petiole; it differs from them by somewhat different (more rounded) anterior lobe with longer setae (Fig. 3d, cf. Fig. $4 \mathrm{e}$ ) and by strikingly long posterior seta and some distinct micropubescence on posterior lobe of gonostylus (Fig. 3d, cf. Fig. 4e and Roháček 1988: Fig. 19). It also differs from that of M. baculum in having a distinct external ventral projection of posterior lobe similar to that of $M$. caelator, which has 3 (not only 2 as in the latter species) spine-like setae or projections. Aedeagal complex (Fig. 3c) of the same general construction as that of M. baculum and M. caelator. Phallapodeme simple, rod-like, with reduced dorsal keel. Postgonite relatively robust (although less than that of $M$. baculum, cf. Fig. 4f) and heavily sclerotized, with more robust proximal part bearing 2 microsetulae on attached remnant of pregonite and more slender, apically slightly bent distal part bearing 3 microsetulae at anterior margin and differing from that of M. baculum and $M$. caelator in having plain (not tuberculate or serrate, cf. Fig. 4f) apex. Aedeagus formed by simple compact phallophore and relatively large distiphallus. Distiphallus rather weakly sclerotized (membranous mainly distally where dilated and forming 2 lobes) and with more sclerotized dorsal and ventral parts in proximal two-thirds. Ejaculatory apodeme reduced, very small, as in both closest relatives.

Female. Unknown.

Etymology. The species is named by a Latin adjective "speluncana" (derived from spelunca = burrow), because the type specimens were found in abandoned burrows of European Rabbit (Oryctolagus cuniculus).

Biology. Both type specimens of Minilimosina speluncana $\mathbf{s p .}$. . were collected (as given by data on their labels written in Czech) in abandoned burrows of European Rabbit. Similarly to its relatives, this species also surely has saprophagous larvae and probably develops in various organic debris in this habitat. However, this does 


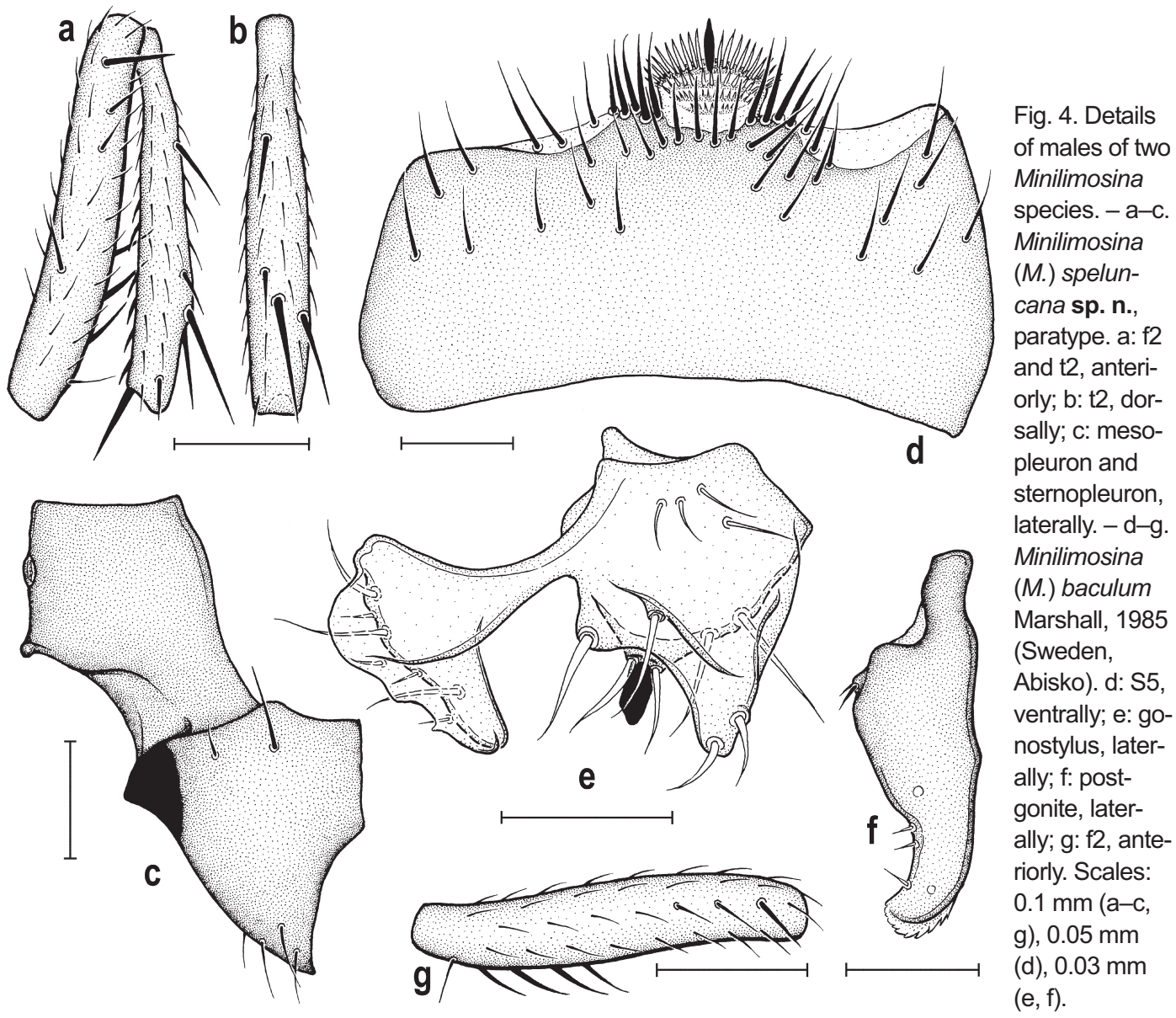

not mean that it has to be exclusively associated with burrows; more probably it can also live in other terricolous habitats with enough supply of rotting plant and animal matter. Adults were collected in November. mia).

Distribution. Czech Republic (Central Bohe-

Discussion. The new species belongs to the subgenus Minilimosina (Minilimosina) Roháček, 1983 currently comprising 31 species in the world, as catalogued by Roháček et al. (2001) and Marshall et al. (2011), plus those described recently by $\mathrm{Su}$ (2011) and Papp (2017).

Minilimosina speluncana $\mathbf{s p .}$. proved to be most closely allied to M. baculum Marshall, 1985 and M. caelator Roháček, 1988 due to similarly formed gonostylus (with distinctively clubbed anterior lobe) and construction of the aedeagal complex. According to Roháček (1988), these species obviously belong to the Minilimosina tenera group, a clade first recognized by Marshall (1985, Fig. 216), which can be characterized by the following 3 synapomorphies: distinctly developed anterior lobe of gonostylus, robust postgonite and long sinuate seta on male cercus. Most species of this group, including $M$. speluncana sp. n. and $M$. caelator, also bear an external ventral spinose process (Fig. 3d) of the posterior lobe of distiphallus (this is reduced only in M. baculum, see Fig. 4e). Consequently, the $M$. tenera group now includes 6 species: $M$. tenera Roháček 1983, M. accinta Marshall, 1985, M. pulpa Marshall, 1985, M. baculum Marshall, 1985, M. caelator Roháček, 1988 and $M$. speluncana $\mathbf{s p .} \mathbf{n}$.

Inasmuch as the females of the latter two species remain undescribed it is not possible to demonstrate their inter-relationships also by apomorphic characters of the female postabdomen. Judging from the male characters, $M$. 
speluncana $\mathbf{s p .} \mathbf{n}$. seems to be somewhat intermediate between $M$. baculum and $M$. caelator because of sharing with $M$. baculum the multiple comb-like armature of male S5 (cf. Fig. 3f and 4d) and unmodified male S6 while with $M$. caelator the spinose ventral external projection of the posterior part of gonostylus, the distally dilated distiphallus and also only 3 small interfrontal setae and the male mid femur with only 3 curved ventral setae in the proximal half(Fig. 4a). On the other hand, M. baculum and M. caelator share a similarly hammer-like anterior clubbed lobe of gonostylus (see Fig. 4e and Roháček 1988: Fig. 19) and the finely serrate or tuberculate apex of the (more robust) postgonite (Fig. 4f and Roháček 1988: Fig. 20). Based on the synapomorphies discussed above, M. speluncana $\mathbf{s p .} \mathbf{n}$. is probably closer to $M$. caelator (which is more derived due to strongly modified male S5 and S6) while $M$. baculum seems to be the (more ancestral) sister group to this pair.

It is noteworthy that representatives of the $M$. tenera group have only been recorded from North America and Europe - no species of this group has hitherto been described from the E. Palaearctic (cf. Su et al. 2015), Oriental (Roháček et al. 2001, Marshall et al. 2011) or Afrotropical Regions (Papp 2017).

In the key to European species of the subgenus Minilimosina (s. str.) by Roháček (1993), the new species runs to couplet $9(8)$ which can be modified as follows:

9(8) Male S5 posteromedially with a chisel-like process terminated by a small comb of spinulae; male S6 with similar chisel-like process attached to that of S5 (Roháček 1988: figs 15, 16). Female unknown.

M. caelator Roháček, 1988

- Male S5 with posteromedial structure flat, armed with several combs of spines (Figs 3f, 4d); S6 without projection.

10(9)Frons with 4 relatively long interfrontal setae. Male $f_{2}$ ventrally with 4 curved setae in proximal half (Fig. 4g). Posteromedial structure of male S5 short, with a robust darker medial spine among fine pale spines of posterior row; setae on disc of S5 short (Fig. 4d); gonostylus with anterior lobe more hammer-like and its posterior lobe lacking external ventral spinose process (Fig. 4e); postgonite robust and its apex finely serrate (Fig. 4f).

M. baculum Marshall, 1985

Frons with only 3 short interfrontal setae. Male $f_{2}$ ventrally with 3 curved setae in proximal half (Fig. 4a). Posteromedial structure of male S5 long and covered by up to 7 combs of pale spines; setae on disc of S5 longer (Fig. 3f); gonostylus with anterior lobe more clubbed and its posterior lobe with distinct external ventral spinose process (Fig. 3d); postgonite more slender and its apex simple (Fig. 3c).

M. speluncana $\mathbf{s p .} \mathbf{n}$.

\subsection{Synopsis of Sphaeroceridae species recorded from burrows}

\subsubsection{Copromyzinae}

Crumomyia fimetaria (Meigen, 1830) - pholeoxenous

Rabbit: B, 21.III.1999, 1 ㅇ.

Crumomyia notabilis (Collin, 1902) - pholeophilous

Rabbit: N, 18.IV.1996, 19; B, 28.XI.1996, $10 \hat{0}$.

Fox: N, 20.XI.1995, 3ð3우 27.XI.1995, 19 ; Z, 20.X.1999, 1 సै6우.

Crumomyia pedestris (Meigen, 1830) - pholeoneutral to pholeophilous

Rabbit: N, 13.XII.1995, 19 f. macropt.

\subsubsection{Limosininae}

Apteromyia claviventris (Strobl, 1909) pholeophilous

Rabbit: N, 17.XI.1995, 2ð19; 28.XI.1995,

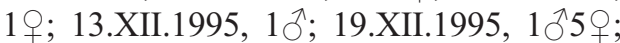
28.XII.1995, 1ㅇ; 18.IV.1996, 2ð23웅

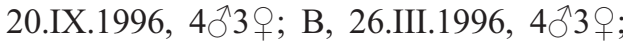
9.IV.1996, 8त21웅 5.XI.1996, 14수오 (1ठ1ㅇ immatures); 20.IX.1996, 2ふ11웅

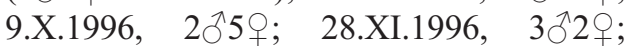

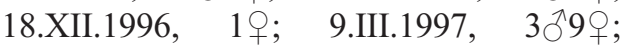

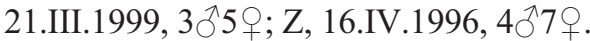

Fox: N, 20.XI.1995, 6^4; 27.XI.1995, 2§;

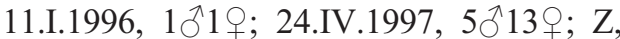




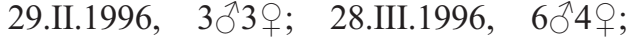

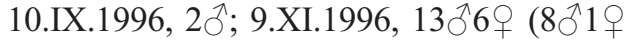
immatures); 26.XI.1996, $6 \bigcirc 12$ ㄱ 16.II.1998,

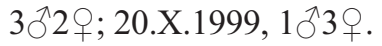

Leptocera caenosa (Rondani, 1880) - pholeoneutral to pholeophilous

Rabbit: B, 20.IX.1996, 2ᄋ; 9.X.1996, 10; 28.XI.1996, $1{ }^{\widehat{\lambda}} 1$ ㅇ․

Minilimosina (M.) parvula (Stenhammar, 1855) - pholeoneutral

Rabbit: B, 9.IV.1996, 19; 5.XI.1996, 19; 20.IX.1996, 1ठ̋; 28.XI.1996, 1ठ̋; Z, 16.IV. 1996, 1 우.

Minilimosina (M.) speluncana $\mathbf{s p .}$ n. - pholeophilous?

Rabbit: B, 5.XI.1996, 2今.

Pteremis fenestralis (Fallén, 1820) 19 - pholeophilous

Rabbit: B, 26.III.1996, 1 f. macropt.

Pullimosina (P.) heteroneura (Haliday, 1836) pholeoneutral

Fox:Z, 9.XI.1996, $3{ }^{\circledR} 4$ 우; ); 26.XI.1996, 1 ㅇ․

Pullimosina (P.) moesta (Villeneuve, 1918) pholeoneutral

Rabbit: B, 9.X.1996, 5 9.

Pullimosina (P.) pullula (Zetterstedt, 1847) pholeophilous

Rabbit: N, 28.XI.1995, 29; 13.XII.1995, 2; B, 5.XI.1996, 1; 9.X.1996, 4 ㅇ.

Fox: Z, 29.II.1996, 1 . .

Spelobia czizeki (Duda, 1918) - pholeophilous to pholeobiont

Rabbit: N, 17.XI.1995, 3ð3\%; B, 9.IV.1996, $1{ }^{\lambda}$.

Fox: N, 11.I.1996, 1ð; Z, 29.II.1996, 1ð;

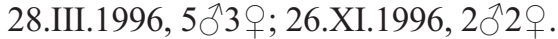

Spelobia palmata (Richards, 1927) - pholeoneutral

Rabbit: B, 5.XI.1996 1; 20.IX.1996, 4; 9.X.1996, 1 ; ; 9.III.1997, 1 Љ3 $q$.

Fox: Z, 9.XI.1996, 1; 26.XI.1996, 10; 20.X.1999, 2 ㅇ.

Spelobia parapusio (Dahl, 1909)-pholeoxenous

Rabbit: N, 13.XII.1995, 3 ㅇ.

Spelobia pseudonivalis (Dahl, 1909) - pholeobiont

Rabbit: N, 13.XII.1995, 1ठ f. brach.; B, 9.IV.1996, 19 f. submacropt.

Fox: N, 20.XI.1995, $1 \overbrace{}^{\Uparrow}$ f. brach.; 27.XI. 1995, 1 ๙ f. brach.
Spelobia talparum (Richards, 1927) - pholeobiont

Rabbit: N, 7.XI.1995, 19; 17.XI.1995,

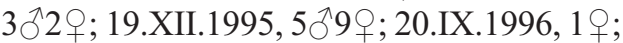
B, 18.XII.1996, 1ð1; Z, 16.IV.1996, 2 \% .

Fox: N， 20.XI.1995, 1ðَ; 27.XI.1995, 10ð11; 11.I.1996, 13ð8ㅇ; Z, 29.II.1996,

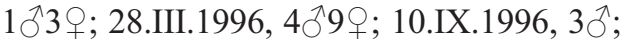

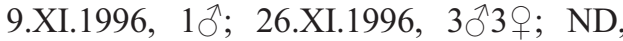
8.IV.1996, 10̄.

Telomerina flavipes (Meigen, 1830) - pholeoneutral

Rabbit: B, 20.IX.1996, 1 . .

Terrilimosina racovitzai (Bezzi, 1911) - pholeophilous

Rabbit: N, 17.XI.1995, 1 ๙.

Fox: Z, 16.II.1998, 1 ㅇ․

\subsection{Sphaeroceridae species composition, dominance and constancy}

\subsubsection{Rabbit burrows}

Altogther 17 species (3 Copromyzinae, 14 Limosininae) were recorded (Table 1). Apteromyia claviventris strongly predominated $(\mathrm{D}=62 \%)$ but also Spelobia talparum was a eudominant species $(\mathrm{D}=14 \%)$. No dominant species was recorded but there were 6 subdominants, viz, $S$. palmata $(\mathrm{D}=4.4 \%)$, Pullimosina pullula $(\mathrm{D}=$ $3.9 \%)$, S. czizeki (D = 3.1\%), and Leptocera caenosa, Minilimosina parvula and Pullimosina moesta (all D $=2.2 \%$ ). Only 1 species $(S$. parapusio) was recedent and the remaing 8 subrecedent. Only the eudominant Apteromyia claviventris occurred in the majority of samples and is therefore a euconstant species $(\mathrm{C}=88.8 \%)$. No species was constant, and only 4 species had constancy higher than $20 \%$.

\subsubsection{Fox burrows}

Only 9 species (1 Copromyzinae, 8 Limosininae) were found. Again, Apteromyia claviventris (D = $45.7 \%$ ) and Spelobia talparum (D =33.5\%) were eudominant species and markedly predominated over other species of the community, resembling the situation in rabbit burrows. By contrast, there were 2 dominant species, Crumomyia notabilis 
Table 1. Species composition, abundance ( $n$ ), dominance (D) and constancy (C) of Sphaeroceridae found in burrows of rabbit (Oryctolagus cuniculus) (18 samples) and fox (Vulpes vulpes) (13 samples) in the vicinty of Nymburk (Czech Republic). $\mathrm{C}=\mathrm{S}_{\mathrm{s}} / \mathrm{S} \times 100(\%)\left(\mathrm{S}=\right.$ total number of samples from burrows, $\mathrm{S}_{\mathrm{s}}=$ number of samples in which the species was found); $D=N_{i} / N \times 100(\%)\left(N=\right.$ total number of specimens, $N_{i}=$ number of specimens of $i^{\text {th }}$ species); $n=$ number of specimens.

\begin{tabular}{|c|c|c|c|c|c|c|}
\hline \multirow[b]{2}{*}{ Species } & \multicolumn{3}{|c|}{ Rabbit burrows } & \multicolumn{3}{|c|}{ Fox burrows } \\
\hline & $n$ & $\mathrm{D}(\%)$ & $\mathrm{C}(\%)$ & $n$ & $\mathrm{D}(\%)$ & $\mathrm{C}(\%)$ \\
\hline Apteromyia claviventris & 142 & 62.0 & 88.8 & 97 & 45.7 & 92.3 \\
\hline Spelobia talparum & 32 & 14.0 & 27.8 & 71 & 33.5 & 69.2 \\
\hline Spelobia palmata & 10 & 4.4 & 22.2 & 4 & 1.9 & 23.1 \\
\hline Pullimosina $(P$.$) pullula$ & 9 & 3.9 & 22.2 & 1 & 0.5 & 7.7 \\
\hline Spelobia czizeki & 7 & 3.1 & 11.1 & 14 & 6.6 & 30.8 \\
\hline Leptocera caenosa & 5 & 2.2 & 16.7 & - & - & - \\
\hline Minilimosina (M.) parvula & 5 & 2.2 & 27.8 & _ & _- & _- \\
\hline Pullimosina $(P$.$) moesta$ & 5 & 2.2 & 5.6 & - & - & - \\
\hline Spelobia parapusio & 3 & 1.3 & 5.6 & _- & _- & _- \\
\hline Crumomyia notabilis & 2 & 0.9 & 11.1 & 14 & 6.6 & 23.1 \\
\hline Minilimosina (M.) speluncana sp. $\mathbf{n}$. & 2 & 0.9 & 5.6 & - & - & - \\
\hline Spelobia pseudonivalis & 2 & 0.9 & 11.1 & 2 & 0.9 & 15.4 \\
\hline Crumomyia fimetaria & 1 & 0.4 & 5.6 & - & - & - \\
\hline Crumomyia pedestris & 1 & 0.4 & 5.6 & - & - & - \\
\hline Pteremis fenestralis & 1 & 0.4 & 5.6 & - & - & - \\
\hline Telomerina flavipes & 1 & 0.4 & 5.6 & - & - & _- \\
\hline Terrilimosina racovitzai & 1 & 0.4 & 5.6 & 1 & 0.5 & 15.4 \\
\hline Pullimosina $(P$.$) heteroneura$ & - & - & - & 8 & 3.8 & 15.4 \\
\hline Total & 229 & 100.0 & - & 212 & 100.0 & - \\
\hline
\end{tabular}

and $S$. czizeki (both $\mathrm{D}=6.6 \%$ ), no subdominant, 1 recedent and 3 subrecedent species in fox burrows. Apteromyia claviventris was euconstant again $(\mathrm{C}=92.3 \%)$ but there was also one constant species, $S$. talparum $(\mathrm{C}=69.2 \%)$ and 3 more species were present in more than $20 \%$ of samples.

\subsection{Similarity of Sphaeroceridae communities in burrows of rabbit and fox}

A total of 18 species was recorded from both habitats together; in rabbit burrows there were 17 species, in fox burrows only 9 species (Table 1). Consequently, the species diversity of Sphaeroceridae associated with rabbit burrows was almost double to that in fox burrows. Eight species were common to both types of burrows. The similarity of species' spectra in the two communities (expressed by Sörensen's index S $=61.5 \%$ ) was relatively high due to the fact that almost all ( 8 out of 9) species found in fox burrows also occurred in rabbit burrows. As stated above, the two most dominant and constant species (A. claviventris and $S$. talparum) were common to both rabbit and fox burrow communities but they differed in representation of other categories of dominance and constancy.

\subsection{Assessment of affinity of Sphaeroceridae species to mammal burrows}

The classification of habitat affinity of each species recorded from rabbit and fox burrows is given above in section 3.2. Only two species, Spelobia pseudonivalis and S. talparum, are considered to be preferentially associated with mammal burrows, runs and nests and, therefore, can be classified as pholeobiont species (see also Roháček 1982b: 216). Their classification is thus in agreement with Hackman $(1965,1967)$, who considers them eucoenic for this habitat. Spelobia czizeki (pholeophilous to pholeobiont) seems to be the next most closely linked with this habitat because (in Central Europe) it occurs subequally 
Table 2. Comparison of communities of Sphaeroceridae recorded from mammal burrows, runs and nests in Europe. Only communities with 9 or more species are included. Sources: 1 - this study (fox; rabbit), 2 - Richards (1930) (rabbit; small rodents: Microtus spp., Apodemus sp., Mus musculus, Rattus norvegicus; mole), 3 - Okely (1974) (rabbit), 4 - Rotheray (1991) (rabbit; small rodents: Arvicola terrestris, Microtus agrestis, Rattus norvegicus), $\mathbf{5}$ - Hackman (1963a) (small rodents: Lemmus lemmus, Clethrionomys rufocanus), 6 - Hackman (1963b) (small rodents: Microtus arvalis, Clethrionomys glareolus), 7 - Hackman (1967) (small rodents: Arvicola terrestris; mole), 8 - Baumann (1977) (small rodents: Microtus spp., Clethrionomys glareolus); 9 - Roháček (1984) (small rodents: Microtus agrestis). Nomenclature of the formerly recorded species was updated following Roháček et al. (2001) and Marshall et al. (2011) including the misidentified species. Abbreviations of affinities: pb - pholeobiont, pn - pholeoneutral, pp - pholeophilous, px - pholeoxenous.

\begin{tabular}{|c|c|c|c|c|c|c|c|c|c|c|c|c|c|c|c|}
\hline \multirow[b]{3}{*}{ Species } & \multicolumn{14}{|c|}{ Burrows of } & \multirow{3}{*}{$\begin{array}{l}\text { Affi- } \\
\text { nity }\end{array}$} \\
\hline & \multirow{2}{*}{$\frac{\text { Fox }}{1}$} & \multicolumn{4}{|c|}{ Rabbit } & \multicolumn{7}{|c|}{ Small rodents } & \multicolumn{2}{|c|}{ Mole } & \\
\hline & & 1 & 2 & 3 & 4 & 2 & 5 & 6 & 7 & 8 & 9 & 4 & 2 & 7 & \\
\hline Ischiolepta crenata & & & & & & & & & & & + & + & & & pn-pp \\
\hline Ischiolepta denticulata & & & & & & & & & + & & & + & & & pn-pp \\
\hline Ischiolepta micropyga & & & & & & & & & & & + & & & & pn-pp \\
\hline Ischiolepta nitida & & & & & & + & & + & & & + & & & & pn \\
\hline Ischiolepta pusilla & & & & + & & & & & & + & + & + & & + & pn \\
\hline Ischiolepta scabricula & & & & + & & & & & & & & & & & $\mathrm{px}$ \\
\hline Sphaerocera monilis & & & & + & & & & & & & + & & & & pn \\
\hline Copromyza borealis & & & & & & & + & + & & & & & & & pn-pp \\
\hline Copromyza equina & & & & & + & & & & & & & & & & pn \\
\hline Copromyza neglecta & & & & & & & & & & & + & & & & $\mathrm{pp}$ \\
\hline Copromyza nigrina & & & + & & + & + & + & & & & & & + & & $\mathrm{pn}$ \\
\hline Copromyza stercoraria & & & & & + & & + & + & + & + & + & + & & & $\mathrm{pp}$ \\
\hline Crumomyia fimetaria & & + & & + & + & + & + & + & & & + & & & + & $\mathrm{px}$ \\
\hline Crumomyia gelida & & & & & & & + & & & & & & & & $\mathrm{pp}$ \\
\hline Crumomyia glabrifrons & & & & & & & & & & & + & & & & pn \\
\hline Crumomyia nigra & & & & + & & & & & & & & & & & pn \\
\hline Crumomyia nitida & & & & & & & & & & & + & & & + & pn \\
\hline Crumomyia notabilis & + & + & & & + & & & + & + & + & + & + & & + & $\mathrm{pp}$ \\
\hline Crumomyia pedestris & & + & & & & & & & & & & & & + & pn-pp \\
\hline Crumomyia pruinosa & & & & & & & + & & & & & & & & $\mathrm{pp}$ \\
\hline Lotophila atra & & & + & & & & & + & & & + & & & & $\mathrm{pn}$ \\
\hline Apteromyia claviventris & + & + & & + & + & + & + & + & & + & & & & + & $\mathrm{pp}$ \\
\hline Aptilotus paradoxus & & & & & & & & & & & + & & & & pn-pp \\
\hline Bifronsina bifrons & & & & + & & + & & & & + & & & & & pn \\
\hline Chaetopodella scutellaris & & & & & + & + & & & & & + & & & & pn \\
\hline Coproica hirtula & & & & + & & & & & & & & & & & pn \\
\hline Coproica pusio & & & & + & & & & & & & & & & & pn \\
\hline Coproica vagans & & & & & & & & & & & + & & & & pn \\
\hline Elachisoma aterrimum & & & & + & & & & & & & & & & & pn \\
\hline Eulimosina ochripes & & & & & & & & & & & + & & & & pn \\
\hline Gigalimosina flaviceps & & & & & & & & & & & + & & & + & $\mathrm{px}$ \\
\hline Gonioneura spinipennis & & & & + & & & & & & & & & & & pn \\
\hline Herniosina bequaerti & & & + & & + & + & & & & + & + & + & + & & $\mathrm{pp}$ \\
\hline Herniosina horrida & & & & & & & & & & & + & & & & $\mathrm{pp}$ \\
\hline Leptocera caenosa & & + & & & & & & + & & & & + & + & & pn-pp \\
\hline Leptocera fontinalis & & & + & + & & + & + & & & & & + & + & & pn \\
\hline Leptocera oldenbergi & & & + & + & & & & & & & & & & + & $\mathrm{pn}$ \\
\hline Limosina silvatica & & & & & & & & & & & + & & & + & pn \\
\hline Minilimosina fungicola & & & + & & + & + & & & + & & + & & & + & pn \\
\hline Minilimosina parvula & & + & & & & & & & & & & & & & pn \\
\hline Minilimosina speluncana sp.n. & & + & & & & & & & & & & & & & $\mathrm{pp}$ \\
\hline Minilimosina vitripennis & & & & & & + & & & & & & + & & + & pn \\
\hline Opacifrons coxata & & & & & & & & & + & & + & & & & $\mathrm{px}$ \\
\hline
\end{tabular}


Table 2, continued

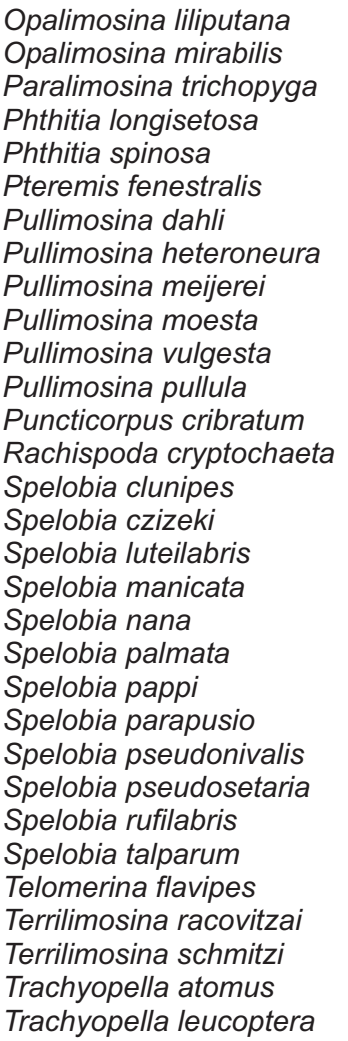

Opalimosina liliputana

Opalimosina mirabilis

prichopyga

Phthitia spinosa

Pteremis fenestralis

Pullimosina dahli

Pullimosina heteroneura

Pullimosina meijerei

Pullimosina moesta

Pullimosina vulgesta

Pullimosina pullula

Puncticorpus cribratum

Spelobia clunipes

Spelobia czizeki

Spelobia luteilabris

Spelobia manicata

Spelobia nana

Spelobia palmata

Spelobia pappi

Spelobia parapusio

Spelobia pseudonivalis

Spelobia pseudosetaria

Spelobia rufilabris

Trachyopella leucoptera

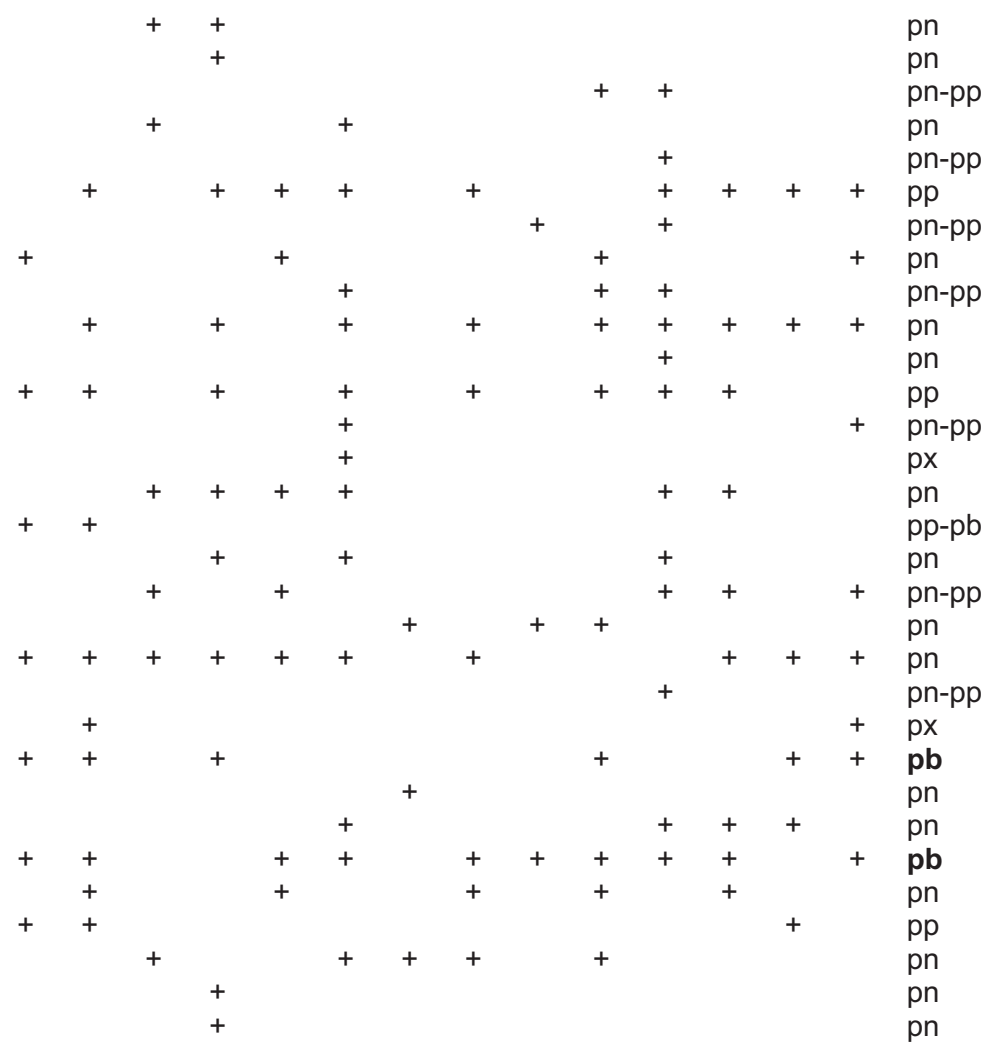

$\begin{array}{llllllllllllll}9 & 17 & 12 & 24 & 16 & 23 & 10 & 16 & 9 & 16 & 36 & 18 & 9 & 20\end{array}$ frequently in burrows and in large subterraneous habitats (like caves, cellars, mine galleries). For biology of these species, see Roháček (1983). It should be stressed that pholeobiont and also some pholeophilous species have not to be necessarily abundant and dominant in burrows. For example, S. pseudonivalis seems to be generally rare (but see Baumann 1977), although exclusively restricted to subterraneous habitats created by mammals.

Pholeophilous species can be divided in two groups:

(i) Species regularly occurring (and developing) in burrows but also (with some preference) associated with caves and other large subterraneous cavities. This group includes Crumomyia notabilis and Terrilimosina racovitzai, which seem to be more closely confined to burrows (see Roháček 1982b, 1983, 1991a) than the second group. (ii) Species often occurring in mammal nests and burrows but mainly living terricolously in small soil crevices, leaf litter, wood detritus and under layers of rotting vegetation. Apteromyia claviventris, Pteremis fenestralis, Pullimosina (P.) pullula and possibly Minilimosina speluncana sp. n. belong to this group but $A$. claviventris seems to be somewhat transient to group (i), because it also occurs frequently in caves and cellars (Roháček 1983). The majority of the species discussed above are distinctly psychrophilous (cold-loving) and dark-loving, which enables them to successfully survive in the subterraneous habitats.

The pholeoneutral species do not display any distinct preference for nests and burrows of mammals but often occur there because of their wide habitat, substrate and microclimate tolerance and enough supply of larval food (rotting animal and 
plant matter). They form an unimportant component of the sphaerocerid burrow community except for 2 species classified as "pholeoneutral to pholeophilous" which I will discuss in some detail below.

Crumomyia pedestris is a wing polymorphic species, which is usually strongly brachypterous to micropterous (see Roháček 1991a, 2012). It lives terricolously in very damp habitats, such as boggy meadows, alluvial alder forest, etc., and its larvae develop in dead snails. However, its rare submacropterous to fully winged form is known to occur (in the wild) almost exclusively in populations inhabiting runs of small mammals in drier habitats (Roháček 1975, 1991a, 2012, Papp 1976). Consequently, there is a distinct affinity of this species (at least of some its populations) to nests and runs of mammals, which is confirned here by finding a macropterous female of $C$. pedestris in a rabbit burrow.

Leptocera caenosa represents a different case. This polysaprophagous (predominatly necrophagous) species is habitat tolerant but seems to preferentially occupy dark or at least shaded habitats including caves, cellars, septic tanks, rooms in houses, etc, provided that there is a good source of breeding substrate for larvae, i.e. rotting matter of animal origin. It is known to form synanthropic populations (Roháček 1982a, 1991b), becoming sometimes overpopulated indoors, including schools and hospitals (Fredeen \& Taylor 1964, Nash \& O'Connor 1982). However, the species is also known to occur in mammal burrows (Richards 1930, Hackman 1963b) and even in wasp nests (Richards 1930), particularly if the habitat contains carrion of the host animal.

Carrion in burrows is also attractive for several other species of Sphaeroceridae, treated here as pholeoneutral, such as Minilimosina (M.) parvula, Spelobia palmata and Telomerina flavipes, which occurred in rabbit and fox burrow assemblages probably on this substrate.

The two pholeoxenous species, Crumomyia fimetaria and Spelobia parapusio recorded here are both, largely or exclusively, mycophagous but can be attracted into burrows by fungi growing on rotting organic debris, which can be the reason of several other published records from mammal nests and burrows (see Table 2).

\section{Discussion}

The material of Sphaeroceridae (altogether 441 specimens, Table 1) obtained from burrows of European Rabbit (229 specimens) and Red Fox (212 specimens) in central Bohemia (the Czech Republic) is the most numerous ever found in this habitat. Falcoz (1915) did not record Sphaeroceridae from rabbit burrows at all, and Richards (1930) listed 12 species of the family from the same habitat without abundance data. The specimens reared and collected as adults by E. B. Basden from burrows of rabbit in Britain include 16 species of Sphaeroceridae represented by a total of 63 specimens (Rotheray 1991: 14-16). The richest composition of Sphaeroceridae in rabbit burrows and tunnels was found in England by Okely (1974) who recorded 24 species (based on puparia collected from bait exposed in this habitat). Only the assemblages of Sphaeroceridae reported from rabbit burrows by Richards (1930: 327), Okely (1974) and Rotheray (1991: 14-16) can be compared with that found in central Bohemia and presented here (Table 2). Unexpectedly, these rabbit-associated communities were not found to be mutually similar, with the highest index of similarity being only $\mathrm{S}=36.4 \%$ of the community ascertained here and that by Rotheray (1991) (rabbit communities 1 and 4 in Table 3).

Published data on Sphaeroceridae from fox burrows are yet poorer - only 2 specimens of a single species (Telomerina flavipes) was reared by E. B. Basden (see Rotheray 1991: 17). The data on sphaerocerid assemblages in burrows of European Badger found in Great Britain and Ireland (Payne 1979, 1982, Hancox 1988, Sleeman $\&$ Bond 2003) are similarly insufficient, each recording only 1-4 species and, therefore, cannot be used to compare communities in fox and badger burrows.

Consequently, the assemblages of Sphaeroceridae recorded here from burrows of rabbit and fox were compared not only with those in most similar habitats (i.e. rabbit burrows, see above) but also with those recorded from burrows, runs and nests of small mammals (various small rodents and mole) by Richards (1930), Hackman (1963a, b, 1967), Baumann (1977), Roháček (1984) and Rotheray 1991) to test degrees of their similarity (Tables 2 and 3). However, only the 
Table 3. Indices of similarities between communities of Sphaeroceridae from mammal burrows, runs and nests. Only communities with 9 or more species are included. For numbering of communities, see Table 2. Three highest values of similarity indices in bold, lowest one with an asterisk $\left(^{*}\right)$, lowest sum of percentages of similarity indices with a cross $\left(^{+}\right)$. Sum $\%$ : total sum of percentages of similarity indices between each community and all remaining communities (values both from relevant column and line).

\begin{tabular}{|c|c|c|c|c|c|c|c|c|c|c|c|c|c|c|}
\hline & \multirow{2}{*}{$\frac{\text { Fox }}{1}$} & \multicolumn{4}{|c|}{ Rabbit } & \multicolumn{7}{|c|}{ Small rodents } & \multicolumn{2}{|c|}{ Mole } \\
\hline & & 1 & 2 & 3 & 4 & 2 & 5 & 6 & 7 & 8 & 9 & 4 & 2 & 7 \\
\hline Sum $\%$ & 394.1 & 475.9 & 342.0 & 362.9 & 517.6 & 499.5 & $240.3^{+}$ & 552.1 & 275.0 & 498.9 & 355.1 & 530.2 & 358.1 & 451.3 \\
\hline $\begin{array}{l}\text { Rabbit } \\
1 \\
2 \\
3 \\
4\end{array}$ & $\begin{array}{r}61.5 \\
9.5 \\
24.2 \\
40.0\end{array}$ & $\begin{array}{r}6.9 \\
34.1 \\
36.4\end{array}$ & $\begin{array}{l}27.8 \\
42.9\end{array}$ & 25.0 & & & & & & & & & & \\
\hline $\begin{array}{l}\text { Small } \\
\text { rodents } \\
2 \\
5 \\
6 \\
7 \\
8 \\
9 \\
4\end{array}$ & $\begin{array}{r}25.0 \\
10.5 \\
40.0 \\
22.2 \\
48.0 \\
8.9 \\
29.6\end{array}$ & $\begin{array}{l}35.0 \\
14.8 \\
60.6 \\
15.4 \\
42.4 \\
22.6 \\
51.4\end{array}$ & $\begin{array}{l}45.7 \\
18.2 \\
28.6 \\
19.0 \\
35.7 \\
20.8 \\
33.3\end{array}$ & $\begin{array}{r}38.3 \\
11.8 \\
35.0 \\
6.1 \\
40.0 \\
26.7 \\
33.3\end{array}$ & $\begin{array}{l}51.3 \\
30.8 \\
50.0 \\
24.0 \\
43.8 \\
38.5 \\
52.9\end{array}$ & $\begin{array}{l}24.2 \\
51.3 \\
18.8 \\
41.0 \\
40.7 \\
48.8\end{array}$ & $\begin{array}{r}38.5 \\
21.1 \\
30.8 \\
8.7 \\
7.1\end{array}$ & $\begin{array}{l}32.0 \\
50.0 \\
36.4 \\
\mathbf{5 8 . 8}\end{array}$ & $\begin{array}{l}32.0 \\
26.7 \\
37.0\end{array}$ & $\begin{array}{l}30.8 \\
47.1\end{array}$ & 44.4 & & & \\
\hline $\begin{array}{l}\text { Mole } \\
2 \\
7\end{array}$ & $\begin{array}{l}33.3 \\
41.4\end{array}$ & $\begin{array}{l}46.2 \\
48.6\end{array}$ & $\begin{array}{l}28.6 \\
25.0\end{array}$ & $\begin{array}{l}24.2 \\
36.4\end{array}$ & $\begin{array}{l}32.0 \\
50.0\end{array}$ & $\begin{array}{l}37.5 \\
41.9\end{array}$ & $\begin{array}{l}10.5 \\
13.3\end{array}$ & $\begin{array}{l}32.0 \\
38.9\end{array}$ & $\begin{array}{c}0^{*} \\
20.7\end{array}$ & $\begin{array}{l}24.0 \\
33.3\end{array}$ & $\begin{array}{l}17.8 \\
32.1\end{array}$ & $\begin{array}{l}44.4 \\
42.1\end{array}$ & 27.6 & \\
\hline
\end{tabular}

communities with 9 or more species are included in these comparisons. The hypothesis that assemblages of Sphaeroceridae from burrows and tunnels of the same mammal host are similar was not confirmed (Table 3). Surprisingly, the highest similarity $(\mathrm{S}=61.5 \%)$ occurred between communities in the fox and rabbit burrows from the Nymburk vicinity (i.e. from practically the same locality with almost identical climatic and microclimatic conditions). The geographical and climatic situation of the locality seems to be decisive for the composition of the local fauna of Sphaeroceridae in the site, and, consequently, it can be presupposed that also the sphaerocerid assemblage in runs and nests of small mammals in this locality would be similar.

Neither the hypothesis that communities of Sphaeroceridae are similar in burrows of large mammals versus those of small mammals was supported although the similarity of the above assemblages in fox and rabbit burrows would indicate this. The next most similar $(\mathrm{S}=60.6 \%)$ were communities from rabbit burrows in Nymburk (C. Bohemia) and from nests and runs of small voles (Microtus arvalis, Clethrionomys glareolus) in $\mathrm{S}$.
Finland (Hackman 1963b). The only other assemblages approaching the above similarities (with $\mathrm{S}$ $=58.8 \%$ ) were those of small rodents recorded by Rotheray (1991) from Great Britain and by Hackman (1963b) from S. Finland.

It is apparent (Tables 1 and 2) that the communities of Sphaeroceridae in hypogean habitats under extreme climatic conditions are most dissimilar with the majority of others, as demonstrated by the smallest sum of percentages of similarity indices (Table 3, column 5) in community found in runs of small rodents in Northern Lappland (Hackman 1963a). However, the mutually most different proved to be assemblages recorded from runs of Arvicola terrestris in S. Finland by Hackman (1967) (Table 3, column 7) and from nests of moles (Talpa europaea) in England by Richards (1930) (Table 3, line mole 2) which had no species in common.

The list of 74 species of Sphaeroceridae recorded from subterranean nests, burrows, tunnels and runs of mammals in Europe as summarized in Table 2 is far from complete. For example, Crumomyia rohaceki Norrbom \& Kim, 1985 has rather often been found in runs and nests of 
Microtus arvalis and M. agrestis in C. Europe (Roháček 1991a), C. parentela alpicola (Roháček, 1980) once in a burrow of Marmota marmota in Vysoké Tatry Mts., Slovakia (Roháček \& Košel 2003), Minilimosina (Svarciella) guestphalica Duda, 1918 in runs of M. arvalis in the Czech Republic (Roháček 1983), Spelobia baezi (Papp, 1977) in runs of Arvicola sp. in Spain (Roháček 1983), S. belanica Roháček, 1983 in runs of Microtus arvalis and M. agrestis in C. Europe (Roháček 1983, 1995) and Terrilimosina corrivalis (Villeneuve, 1918) in runs of Arvicola terrestris in the Czech Republic (Roháček 1983). Some of these species are even pholeophilous, viz. C. rohaceki and C. parentela alpicola (which otherwise occur in caves) or pholeophilouspholeoneutral (e.g., the terricolous species $S$. belanica and T. corrivalis).

It can be expected that some additional (largely pholeoneutral) species will be found in these small subterraneous mammal habitats in the future, so that the number of Sphaeroceridae occuring there is likely to reach up to 90 species.

Acknowledgements. It is an agreeable duty to thank Dr. B. Mocek (Museum of East Bohemia, Hradec Králové, Czech Republic) who kindly mediated the communication with Dr. L. Daněk and passed his material of Sphaeroceridae to me for study and provided information about the study area and collecting methods. I am particularly obliged to Mr. P. Chandler (Melksham, England) for the British literature on flies in burrows of mammals and for careful review and language revision of the manuscript. This study was financially supported by the Ministry of Culture of the Czech Republic by institutional financing of long-term conceptual development of the research institution (the Silesian Museum, MK000100595), internal grant of the Silesian Museum IGS201806/2018.

\section{References}

Baumann, E. 1977: Untersuchungen über die Dipterenfauna subterraner Gangsysteme und Nester von Wühlmäusen (Microtus, Clethrionomys) auf Wiesen der montanen Region im Naturpark Hoher Vogelsberg. - Zoologische Jahrbücher, Abteilung für Systematik, Ökologie und Geographie der Tiere 104: 368414. [In German.]

Begon, M., Harper, J. L. \& Townsend, C. R. 1996: Ecology: Individuals, populations and communities, $3^{\text {rd }}$ edition. - Blackwell Science, 1068 pp.

Davis, D. H. S. 1934: A preliminary survey of the nest fauna of short-tailed voles (Microtus agrestis and M. hirtus). — Entomologist's Monthly Magazine 70: 96101.
Falcoz, L. 1915: Contribution à l'étude de la faune des microcavernes. Faune des terriers et des nids. - Annales de la Société Linnéenne de Lyon 61: 59-245. [In French.] doi: https://doi.org/10.3406/linly.1915.4233

Falcoz, L. 1921: Matériaux pour l'étude de la faune pholéophile. - 1re note: Diptères, avec la description d'une espèce nouvelle de Sphaerocera Latr. - Bulletin de la Société Entomologique de France, Paris 1921: 137142. [In French.]

Fredeen, F. J. H. \& Taylor, M. E. 1964: Borborids (Diptera: Sphaeroceridae) infesting sewage disposal tanks, with notes on the life cycle, behavior and control of Leptocera (Leptocera) caenosa (Rondani). - Canadian Entomologist 96: 801-808. doi: https://doi.org/ 10.4039/Ent96801-5

Hackman, W. 1963a: On the dipterous fauna of rodent burrows in Northern Lapland. - Notulae Entomologicae 43: $121-131$.

Hackman, W. 1963b: Studies on the dipterous fauna in burrows of voles (Microtus, Clethrionomys) in Finland. - Acta Zoologica Fennica 102: 1-64.

Hackman, W. 1965: Some features of the dipterous fauna of small mammal burrows. - Proceedings of XII. International Congress of Entomology, London 1964: 430.

Hackman, W. 1967: On Diptera in small mammal burrows in Northern Europe and Southern Spain. - Notulae Entomologicae 47: 1-14.

Hancox, M. 1988: The nidicolous fauna of badger setts. Entomologist's Monthly Magazine 124: 93-95.

Hutson, A. M. 2010: Associations of Diptera with other animals and micro-organisms. Association with vertebrates, their nests, roosts and burrows: $315-327$. In: Chandler, P. (ed.): A dipterist's handbook ( $2^{\text {nd }}$ Edition). - The Amateur Entomologist Vol. 15, The Amateur Entomologist's Society, Brentwood, Essex. $525 \mathrm{pp}$.

Krivokhatsky, V. A. 1989: [Investigations of dwellers of mammal burrows in the USSR]. - Vestnik Leningradskogo Universiteta. Biologia. 4(24): 13-18. [In Russian.]

Krivokhatsky, V. A. \& Nartshuk, E. P. 2007: Assemblages of dipterans (Diptera) in burrows of the European Pine Vole Microtus (Terricola) subterraneus Sel.-Long. The "Les na Vorskle (Forest on the Vorskla River)" Nature Reserve (Belgorod Province). — Entomological Review 87(2): 156-158. doi: https://doi.org/ 10.1134/S0013873807020042

Krogerus, R. 1960: Ökologische Studien über nordische Moorarthropoden. - Commentationes Biologicae 21(3): 1-238. [In German.]

Marshall, S. A. 1985: A revision of the New World species of Minilimosina Roháček (Diptera: Sphaeroceridae). - Proceedings of the Entomological Society of Ontario 116: 1-60.

Marshall, S. A., Roháček, J., Dong, H. \& Buck, M. 2011: The state of Sphaeroceridae (Diptera: Acalyptratae): a world catalog update covering the years 2000-2010, with new generic synonymy, new combinations, and 
new distributions. - Acta Entomologica Musei Nationalis Pragae 51(1): 217-298.

Nash, R. \& O'Connor, J. P. 1982: Limnophora exuta and Leptocera caenosa (Insecta: Diptera) new to Ireland. — Irish Naturalists' Journal, Belfast 20(12): 549-550.

Okely, E. F. 1974: Description of the puparia of twenty three British species of Sphaeroceridae (Diptera, Acalyptratae). - Transactions of the Royal Entomological Society of London 126(1): 41-56. doi: https://doi.org/10.1111/j.1365-2311.1974.tb02877.x

Papp, L. 1976: Some terricolous Sphaerocerids and Drosophilids from Hungary (Diptera: Sphaeroceridae and Drosophilidae). — Folia Entomologica Hungarica, S. N., 29(1): 75-86.

Papp, L. 2017: Twenty new species of fifteen genera of the Afrotropical Sphaeroceridae (Diptera). - Acta Zoologica Academiae Scientiarum Hungaricae 63(4): 377-427. doi: https://doi.org/10.17109/AZH.63. 4.377.2017

Payne, R. M. 1979: Flies associated with badgers. — Entomologist's Monthly Magazine 114 (1978): 126.

Payne, R. M. 1982: More flies associated with badgers. Entomologist's Monthly Magazine 118: 162.

Richards, O. W. 1930: The British species of Sphaeroceridae (Borboridae, Diptera). - Proceedings of the Zoological Society of London 1930: 261-345.

Roháček, J. 1975: Die Flügelpolymorphie bei den europäischen Sphaeroceridenarten und Taxonomie der Limosina heteroneura-Gruppe (Diptera). - Acta Entomologica Bohemoslovaca 72: 196-207. [In German.]

Roháček, J. 1982a: Revision of the subgenus Leptocera (s. str.) of Europe (Diptera, Sphaeroceridae). - Entomologische Abhandlungen, Staatliches Museum für Tierkunde in Dresden 46(1): 1-44.

Roháček, J. 1982b: A monograph and re-classification of the previous genus Limosina Macquart (Diptera, Sphaeroceridae) of Europe. Part I. - Beiträge zur Entomologie, Berlin 32: 195-282.

Roháček, J. 1983: A monograph and re-classification of the previous genus Limosina Macquart (Diptera, Sphaeroceridae) of Europe. Part II. - Beiträge zur Entomologie, Berlin 33: 3-195.

Roháček, J. 1984: Acalypterate Diptera of peat-bogs in North Moravia (Czechoslovakia). Part 6. Sphaeroceridae. - Časopis Slezského Muzea, Opava (A), 33: 97131.

Roháček, J. 1988: Two new species of Minilimosina (s.str.) from Europe (Diptera, Sphaeroceridae). - Acta Entomologica Bohemoslovaca 85: 223-230.

Roháček, J. 1991a: Sphaeroceridae (Diptera) of Czechoslovakia. Part 2. Crumomyia Macquart. - Časopis Slezského Zemského Muzea, Opava (A) 40: 1-27.

Roháček, J. 1991b: A monograph of Leptocera (Rachispo$d a$ Lioy) of the West Palaearctic area (Diptera, Sphaeroceridae). - Časopis Slezského Zemského Muzea, Opava (A) 40: 97-288.

Roháček, J. 1993: Herniosina Roháček and Minilimosina Roháček of Europe: two new species, new records and taxonomic notes (Insecta, Diptera: Sphaeroceridae). - Entomologische Abhandlungen, Staatliches Mu- seum für Tierkunde in Dresden 55: 185-203.

Roháček, J. 1995: Sphaeroceridae (Diptera) of the Czech Republic: corrections and additions to the faunal list, with taxonomical notes. - Časopis Slezského Zemského Muzea, Opava (A) 44: 219-240.

Roháček, J. 1998: 3.43. Family Sphaeroceridae: 463-496. - In: Papp, L. \& Darvas, B. (eds), Contributions to a Manual of Palaearctic Diptera. Vol. 3., Higher Brachycera. Science Herald, Budapest. 880 pp.

Roháček, J. 2012: Wing polymorphism in European species of Sphaeroceridae (Diptera). - Acta Entomologica Musei Nationalis Pragae 52(2): 535-558.

Roháček, J. 2016: Herniosina Roháček: revised concept, two new species, new key and atlas of male and female terminalia (Diptera, Sphaeroceridae). — ZooKeys 609: 69-106. doi: https://doi.org/10.3897/zookeys. 609.9459

Roháček, J. \& Košel, V. 2003: Crumomyia glacialis (Meigen, 1830) in Slovakia, with description of the female and notes on variation and biology (Diptera, Sphaeroceridae). - Časopis Slezského Zemského Muzea (A), 51 (2002): 193-198.

Roháček, J. \& Máca, J. 1982: Acalypterate Diptera of peatbogs in North Moravia (Czechoslovakia). Part 2. Ecological classification, Opomyzidae, Anthomyzidae, Asteiidae, Diastatidae, Drosophilidae. - Časopis Slezského Muzea, Opava (A), 31: 193-213.

Roháček, J., Marshall, S. A., Norrbom, A. L., Buck, M., Quiros, D. I. \& Smith, I. 2001: World catalog of Sphaeroceridae (Diptera). — Slezské zemské muzeum, Opava. 414 pp.

Rotheray, G. E. 1989: E. B. Basden's collection of Diptera from bird and mammal nests, and mammal runs, burrows and droppings. - Entomologist's Monthly Magazine 125: 5-8.

Rotheray, G. E. 1991: E B Basden's collection of Diptera from bird and mammal nests and mammal runs, burrows and droppings. - National Museum of Scotland Information Series, 3: 1-46.

Sleeman, D. P. \& Bond, K. G. M. 2003: Flies (Diptera) trapped at badgers' sett in Co. Cork, Ireland. - Entomologist's Gazette 54: 167-170.

Spellerberg, I. F. 1991: Monitoring ecological change. Cambridge University Press, Cambridge. 334 pp.

Su, L. X. 2011: Xiaofenying [Lesser Dung Flies.] — Liaoning University Press, Shenyang, Liaoning, China. 229 pp. [In Chinese.]

Su, L., Liu, G. \& Xu, J. 2015: A review of Minilimosina Roháček (Diptera: Sphaeroceridae) from China. Zootaxa 4007(1):1-28. doi: https://doi.org/10.11646/ zootaxa.4007.1.1

Vysotskaya, S. O. 1978: [Analysis of biocenotic relations between ectoparasites of the Common Vole (Microtus arvalis Pall.) and dwellers of its nests in Eastern Carpathians (Zakarpatskaya Province, Ukrainian SSR]. — Parazitologicheskij Sbornik 28: 73-95.

Vysotskaya, S. O. 1981: [Microbiocenotis of nests of the Common Vole (Microtus arvalis Pall.) in mountain meadows of Zakarpatskaya Province of the Ukrainian SSR]. — Parazitologicheskij Sbornik 30: 69-84. 